\title{
FORT COLLINS SCIENCE CENTER Policy Analysis and Science Assistance
}

\section{Capabilities}

Most resource management decisions involve the integrated use of biological, sociological, and economic information. Combining this information provides a more comprehensive basis for making effective land management and conservation decisions. Toward this end, scientists in the Policy Analysis and Science Assistance Branch (PASA) of the Fort Collins Science Center (FORT) contribute expert knowledge for natural resources management by conducting biological, social, economic, and institutional analyses of conservation policies and management practices.

PASA's mission is to integrate biological, social, and economic research so that resource managers can use the resulting information to make informed decisions and resolve resource management conflicts. PASA scientists pursue and conduct scientific analyses that help agencies and Native American tribes to (1) identify impending policy controversies and areas where social and natural science research is needed to address future policy questions; (2) develop methods and approaches to assist researchers in preparing scientific evidence; (3) assess habitat alteration in a manner consistent with policy needs; and (4) evaluate policy options. Branch scientists also evaluate policy options (e.g., effects of different land treatments, fish and wildlife management practices, or visitor/recreation management practices) in response to specific questions faced by policymakers and managers.

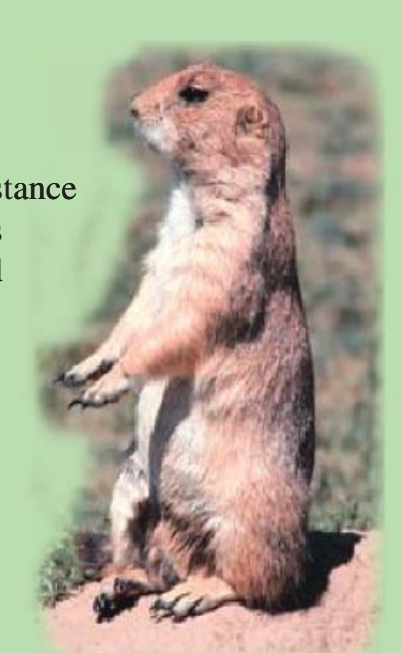

\section{Management, Planning, and Policy Evaluation Project}

\section{Visitor and Citizen Perceptions}

This research is designed to gain information about what the public perceives to be the important elements for sustaining communities and landscapes. Are there certain

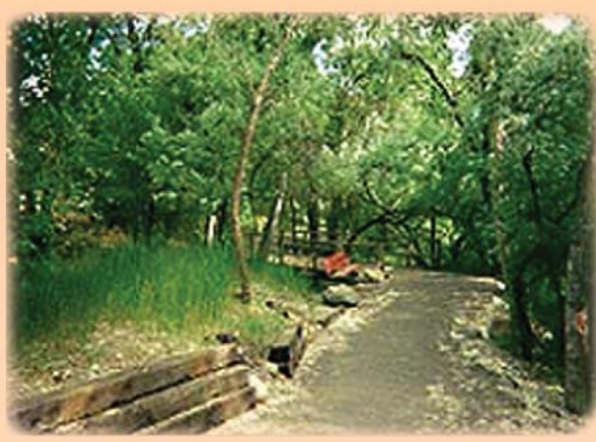
elements that residents of a community or visitors to a protected area think should be preserved, maintained, or restored to attain desired future conditions? The unique approach employed in this study in a national park and two regions of the Colorado Plateau has generated data that have helped managers assess public perceptions and preferences regarding various management scenarios.

\section{Estimation of Socioeconomic Impacts of Management Alternatives}

One example of this research involves the Southern Greater Yellowstone Area. Elk and bison herds inhabiting Grand Teton National Park and the National Elk Refuge represent one of the largest concentrations of free-ranging

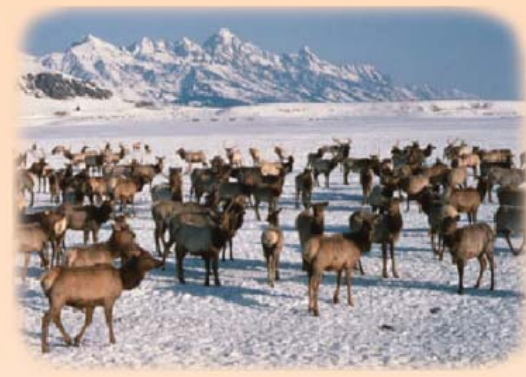

bison and elk in the world. Federal managers are devising a longterm strategy for managing these animals, which migrate across several jurisdictional boundaries. Managers must balance many competing interests and address the economic impact of each proposed alternative. PASA scientists are conducting research to quantify citizens' attitudes, knowledge, and preferences; determine economic values; and estimate the regional economic impacts, including local income and employment effects, related to these proposed management alternatives. Such results yield valuable insights regarding the ramifications of each management option before it is proposed in an Environmental Impact Statement.

\section{Natural Resource Negotiations}

Since 1990, natural resource managers have seen a growing trend to include local stakeholders in the decision-making process. The Legal-Institutional Analysis Model (LIAM), developed by FORT social scientists as a tool for negotiation preparation, is designed to accomplish three goals: (1) plan for participation in a negotiation, (2) predict organizational behavior, and (3) examine likely negotiation strategies. LIAM has been used in collaborative decision-making efforts involving water, natural resource, and wildlife decisions throughout the United States and in Mexico. PASA scientists have also developed and continue to conduct courses in negotiations training in which participants learn and practice the principles, skills, and techniques used in successful natural resource negotiations. The courses are based on research that PASA scientists have conducted since the mid-1980's on multi-party natural research negotiations. For information about upcoming course offerings or to arrange for a course, visit http://www.fort.usgs.gov/products/ training/training.asp. 


\section{Development of Adaptive Land Management Models and Practices Project}

\section{Support to the U.S. Department of Agriculture's (USDA) Conservation Reserve Program}

The USDA Conservation Reserve Program (CRP) is the largest conservation program in U.S. history, affecting land in all 50 states. Over 28 million acres of private land are planted to grasses under the CRP. Benefits to wildlife have been well documented and account in large part for widespread acceptance and several renewals of the program. PASA scientists have been conducting a long-term study looking at changes in CRP grassland composition and how these changes

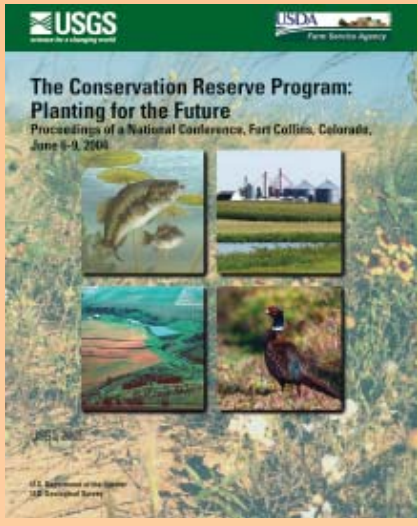
influence habitat quality for different species of wildlife. In addition, PASA scientists surveyed landowners on their perceptions about wildlife issues, the quality of assistance provided by USDA, and long-term management of CRP lands. This helps policymakers understand how the CRP program is working "on the ground" for participating farmers and ranchers. These cooperative studies between the USDA and FORT scientists focus on identification of economically and socially acceptable management practices that achieve long-term wildlife management goals associated with agricultural practices. The resulting information improves the effectiveness of the CRP.

\section{Support to the Comprehensive Conservation Planning Process}

The U.S. Fish and Wildlife Service is required to develop a Comprehensive Conservation Plan (CCP) for each unit of the National Wildlife Refuge System. A CCP guides management decisions and sets goals, objectives, and strategies for achieving refuge purposes. The CCP process offers an opportunity to evaluate and improve habitat and wildlife management. Each CCP must address current and future social and economic conditions. PASA scientists are working with several refuges to (1) provide technical assistance in developing high-quality habitat objectives, and (2) provide and interpret data on the likely social, economic, and institutional results of each CCP management option. PASA scientists have conducted workshops to help refuges develop habitat-based goals and objectives

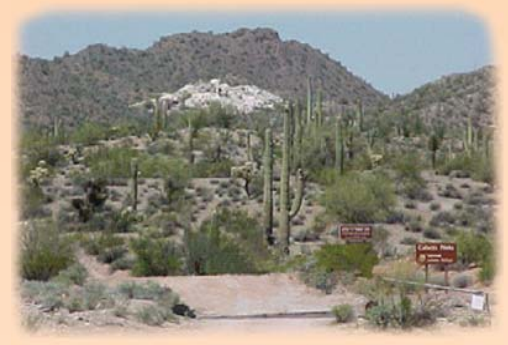
for their CCPs. Altogether, over 200 refuges have benefited from other forms of technical assistance from PASA, including on-site management consultations, simulation modeling, information synthesis, software development, and handbook publication.

\section{International Economic Development and Sustainability}

Many developing countries seek economic development strategies that will sustain their biological and cultural resources. For example, the Yunnan and Sichuan Provinces in Southwest China are among China's most biologically and culturally diverse. Twenty-six of China's 55 minority cultures have significant populations there, and poverty rates are high. Ecosystems range from tropical rain forests to 18,000-foot mountains. The U.S. Geological Survey is cooperating with provincial governments, universities, and the Chinese
Academy of Sciences to build economic development methods that will sustain biological and cultural diversity. Workshops held in the U.S. have trained Chinese scientists in connecting economic development, conservation biology, and GIS/GAP technologies.

PASA scientists provide ongoing technical assistance on economic development and habitat sustainability in China and other countries.

\section{Staff}

Branch Chief: Berton Lee Lamb, Ph.D. Supervisory Social Scientist: water resource policy, conflict resolution, institutional analysis, instream flow policy, natural resource negotiation.

Allen, Arthur, B.S. Wildlife Biologist: USDA conservation policies, agroforestry, habitat assessment, modeling.

Burkardt, Nina, M.A. Social Science Research Analyst: natural resource negotiation, water resource policy, institutional analysis.

Gillette, Shana, Ph.D. Social Scientist: natural resource negotiation, conflict resolution, human health and the environment.

Haire, Sandra, Ph.D. candidate. Ecologist: fire ecology, GIS/remote sensing.

Johnson, Richard L., M.S. Economist: ecological economics, international and development economics, resource economics and public policy, adaptive modeling and management.

Koontz, Lynne, Ph.D. Economist: natural resource policy, regional economic analysis.

Ponds, Phadrea, M.S. Research Wildlife Biologist: human dimensions of wildlife and natural resource management.

Schroeder, Richard, B.S. Wildlife Biologist: habitat modeling, community modeling, habitat assessment, landscape ecology, ornithology.

Sexton, Natalie, M.S. Wildlife Biologist: human dimensions of wildlife management, natural resource management.

Swann, Earlene, M.A. Visual Information Specialist: social science survey development and coordination, training coordination, communications strategies.

Taylor, Jonathan, Ph.D. Social Science Analyst: natural resource negotiation, human perceptions of natural resources.

Vandever, Mark, M.S. candidate. Student Trainee (Rangeland Management Specialist): Rangeland and forest management, USDA conservation programs and policies.

\section{Contact Information}

Berton Lee Lamb, Branch Chief

U.S. Geological Survey, Fort Collins Science Center 2150 Centre Avenue, Building C Fort Collins, Colorado 80526-8118

Tel.970.226.9314 Fax970.226.9230 lee_lamb@usgs.gov

\section{FORT Online}

Find information about FORT science, products, and resources at http://www.fort.usgs.gov

Learn more about the Policy Analysis and Science Assistance Branch at http://www.fort.usgs.gov/research/400/400.asp 